\title{
PEMODELAN TRANSFORMASI DIRECT QUADRATUR (D-Q) PADA KENDALI KECEPATAN MOTOR INDUKSI 3 FASA DENGAN METODE VECTOR CONTROL
}

\author{
Rizana Fauzi ${ }^{1)}$, Muh. Aristo Indrajaya ${ }^{2)}$, Dody Candra $\mathbf{K}^{3)}$ Wirdha $^{4)}$ \\ 1,2,)Dosen Teknik Elektro Universitas Tadulako \\ 2,3.) Dosen Teknik Mekanisasi Pengolahan Politeknik Palu \\ e-mail : rfauzi86@gmail.com
}

\begin{abstract}
The application of the 3 phase induction motor is increasingly developing, this has led to research on speed regulation of 3 phase induction motors is also growing, because the use in industry and especially in hybrid vehicles is increasingly being developed. However, there are several disadvantages of an induction motor, one of which is the non-linear parameter characteristics, especially the rotor resistance, which varies in value for different operating conditions, so that it cannot maintain its speed constantly when a load changes. Therefore, to get constant speed and better system performance against load changes, a controller is needed. This study aims to implement the vector control method in the 3 phase induction motor speed control application in following the reference speed. In vector modeling, the 3 phase parameters (ia, ib and ic) will be transformed into direct quadrature (dq) parameters where in this parameter the setting of the field size and torque can be adjusted separately. In the implementation results, it can be seen that the use of vector control can be used as an approach in regulating the speed of an induction motor.
\end{abstract}

Keyword : induction motor, vector control

\section{PENDAHULUAN}

Aplikasi motor induksi 3 fasa semakin lama semakin berkembang, dikarenakan kehandalannya pada penggunaan di industri dan khususnya pada kendaraan hybrid semakin banyak
dikembangkan.Namun ada beberapa kelemahan motor induksi yang salah satunya adalah karakteristik parameter yang tidak linier, terutama resistansi rotor yang memiliki nilai yang bervariasi untuk kondisi operasi yang berbeda, sehingga tidak dapat mempertahankan kecepatannya secara konstan bila terjadi perubahan beban. Dikarenakan hal tersebut, untuk mendapatkan kecepatan yang konstan dan performa sistem yang lebih baik terhadap perubahan beban dibutuhkan sebuah pengendali. [1]

\section{METODE PENELITIAN}

\subsection{Vector Control}

Vector control adalah metode yang digunakan untuk pengendalian kecepatan pada motor AC, di mana dari sistem coupled diubah menjadi sistem decoupled. [9] Dengan sistem ini arus penguatan dan arus beban motor dapat dikontrol secara terpisah, dengan demikian torsi dan fluksi juga dapat diatur secara terpisah, seperti halnya motor DC. Pada vector control arus penguatan pada dua parameter yaitu medan dan torsi dapat diatur yang akan berdampak langsung dengan perubahan kecepatan pada motor induksi. [10] Pengukuran besarnya medan dapat dilakukan langsung (direct) dengan pemodelan atau bisa dilakukan dengan tidak langsung (indirect) dengan sensor kecepatan rotor. [6] Apabila pengukuran dilakukan secara indirect, berarti parameter yang 
digunakan adalah sensor kecepatan yang kemudian nilai yang diperoleh diumpan balikkan kemudian dibandingkan dengan kecepatan referensi oleh suatu komparator.

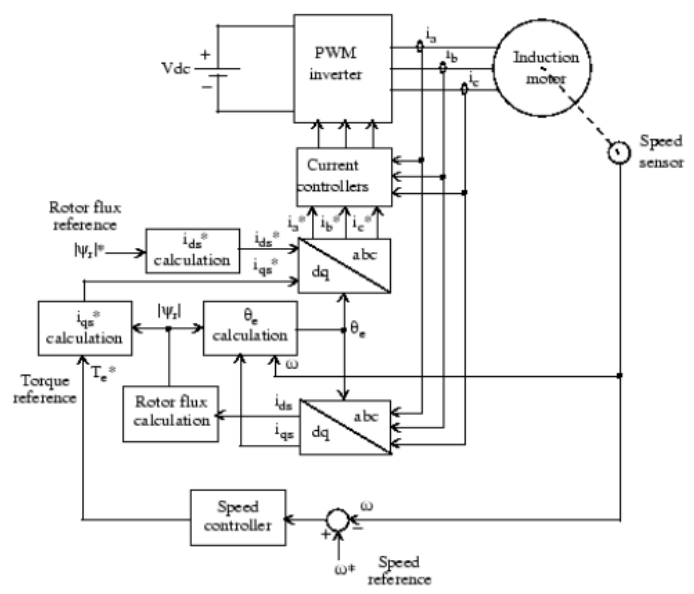

Gambar 1. diagram blok pengaturan kecepatan motor induksi vector control.

Fluks rotor dan torsi dapat dikontrol secara terpisah oleh arus stator direct-axis (ids) dan arus quadratur-axis (iqs) secara berurutan. [4] Besar arus quadratur-axis referensi (i*qs) dapat dihitung dengan torsi referensi $\mathrm{Te}^{*}$ menggunakan persamaan berikut :

$i_{q S}^{*}=\frac{2}{3} * \frac{2}{P} * \frac{L_{r}}{L_{m}} * \frac{T_{e}^{*}}{\lambda_{r}^{*}}$

dengan $\mathrm{Lr}$ adalah induktansi rotor, $\mathrm{Lm}$ adalah induktansi mutual, dan $\lambda \mathrm{r}$ adalah fluks linkage rotor estimasi, yang diperoleh dari persamaan berikut :

$\lambda_{r}=\frac{L_{m} i_{d s}}{1+\tau_{r} S}$

Dengan $\quad \tau_{r}=\frac{L_{r}}{R_{r}}$ adalah konstanta waktu rotor. Besarnya arus direct-axis stator referensi $i_{q s}^{*}$ adalah tergantung dari input fluks referensi $\lambda_{r}^{*}$ yaitu,

$i_{d s}^{*}=\frac{\lambda^{*}}{L_{m}}$ kecepatan slip diperoleh dari perhitungan arus stator referensi $i_{q S}^{*}$ dengan parameter motor.

$\omega_{s l}=\frac{L_{m}}{\lambda_{r}^{*}} * \frac{R_{r}}{L_{r}} * i_{q S}^{*}$

\subsection{Transformasi Clarke dan Park}

Transformasi Clarke atau yang juga sering disebut sebagai transformasi $\alpha \beta$ merupakan transformasi sistem tiga fasa $(\mathbf{a}, b, c)$ menjadi sistem dua fasa $(\alpha, \beta)$ yang stasioner. Jika dianggap arus $\mathrm{a}, \mathrm{b}$, dan $\mathrm{c}$ bernilai sesuai dengan fungsi sinusoidal dan memiliki perbedaan fasa sebesar $120^{\circ}$ satu sama lainnya, maka arus tiga fasa tersebut dapat diubah ke dalam dua fasa yang diam, yaitu sumbu $\alpha-\beta$, atau sumbu $\alpha$ sebagai nilai real-nya, dan sumbu $\beta$ sebagai nilai imajinernya (kerangka referensi stator). Transformasi clarke dapat dilihat pada Gambar 4. berikut.

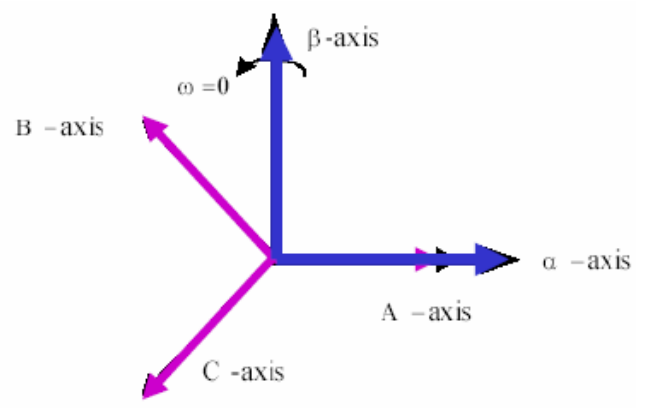

Gambar 2. Transformasi clark

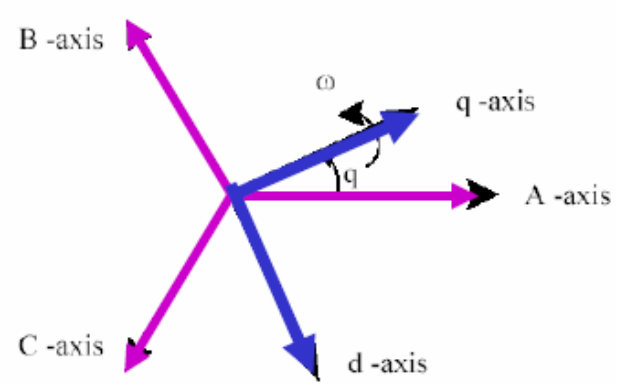

Gambar 3. Transformasi park 
$\operatorname{Arus}_{s}$ pada Gambar 4a. diatas bila dinyatakan sebagai fungsi dari komponen tiga fasa adalah sebagai berikut:

$$
\bar{l}_{s}^{s}=i_{s a} e^{j 0^{o}}+i_{s b} e^{j 120^{o}}+i_{s c} e^{j 240^{o}}
$$

dan dengan menggunakan identitas Euler $e^{j \omega t}=\cos (\omega t)+j \sin (\omega t) \quad$ maka komponen $i_{s \alpha}$ dan $i_{s \beta}$ dari vector $\bar{l}_{s}^{s}$ (dengan super script $\mathrm{s}$ mengimplikasikan kerangka referensi stasioner/stator) dapat dinyatakan sebagai :

$\bar{l}_{s}^{s}=i_{s a}+j i_{s b}$

sehingga persamaan dalam bentuk matriks untuk mengubah komponen tiga fasa menjadi dua fasa, adalah sebagai berikut :

$\left[\begin{array}{l}i_{\alpha} \\ i_{\beta}\end{array}\right]=\sqrt{\frac{2}{3}}\left[\begin{array}{ccc}1 & -\frac{1}{2} & -\frac{1}{2} \\ 0 & \frac{1}{2} \sqrt{3} & -\frac{1}{2} \sqrt{3}\end{array}\right]\left[\begin{array}{l}i_{a} \\ i_{b} \\ i_{c}\end{array}\right]$

dengan konstanta $\sqrt{\frac{2}{3}}$ yang menunjukkan sistem power invariant.

Transformasi Park merupakan transformasi sistem dua fasa stasioner, $\alpha$ dan $\beta$, menjadi sistem dua fasa yang berputar,direct (d) dan quadrature (q) atau seringkali disebut transformasi dq. Dari gambar $8 \mathrm{~b}$ diatas, hubungan antara vector $\bar{l}_{s}^{S}$ pada kerangka referensi stasioner dan vector $\bar{l}_{s}^{e}$ pada kerangka referensi yang bergerak adalah :

$\bar{\imath}_{s}^{e}=\bar{\imath}_{s}^{s} e^{-j \theta}$

persamaan di atas dapat dijabarkan menjadi :

$i_{s d}=j i_{s q}=\left(i_{s \alpha}+j i_{\beta}\right)[\cos (-\theta)+$ $j \sin (-\theta]$

atau bila persamaan di atas dinyatakan dalam matriks, maka:

$\left[\begin{array}{l}i_{s d} \\ i_{s q}\end{array}\right]=\left[\begin{array}{cc}\cos \theta & \sin \theta \\ -\sin \theta & \cos \theta\end{array}\right]\left[\begin{array}{l}i_{s \alpha} \\ i_{s \beta}\end{array}\right]$
Transformasi Clarke di dalam field oriented control motor induksi digunakan untuk mentransformasikan arus stator tiga fasa ( $\mathrm{i}_{\mathrm{a}}$, $i_{b}$, dan $i_{c}$ ) pada bidang stasioner (stationary reference frame) ke arus stator ortogonal dua fasa ( $i_{\alpha}$ dan $i_{\beta}$ ) pada bidang ortogonal (orthogonal reference frame). Sedangkan Transformasi Park digunakan untuk mentransformasikan arus stator $\left(i_{\alpha}\right.$ dan $\left.i_{\beta}\right)$ ke arus stator dua fasa ( $i_{d s}$ dan iqs $)$ pada bidang putar (rotating reference frame).

\subsection{Desain Sistem}

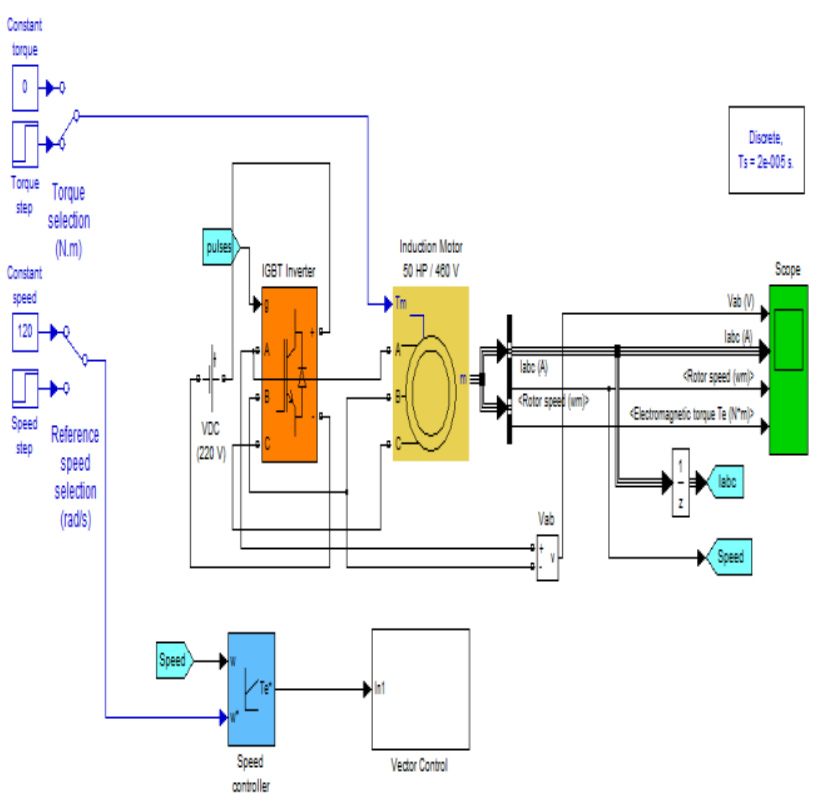

Gambar 5. Blok Desain Sistem

Pada bagan di atas, dapat kita lihat bahwa nilai kecepatan real akan diumpan balikkan ke speed controller untuk kemudian dibandingkan dan selisih errornya akan diproses menggunakan kendali PID sehingga menghasilkan nilai torsi referensi. [7] Nilai torsi referensi tadi kemudian diolah pada blok vector control, untuk kemudian parameter dari torsi referensi tadi dijadikan acuan untuk mengubah nilai-nilai parameter 3 phase menjadi parameter 2 phase rotasional (direct quadrature parameter) berupa nilai arus direct-axis $\left(i_{d s}^{*}\right)$ dan nilai 
arus quadratur-axis $\left(i_{q S}^{*}\right)$ kemudian nilai ini ditransformasikan lagi dengan inverse park menjadi arus sefasa stasioner referensi $\left(i_{a s}^{*}, i_{b s}^{*}, i_{c S}^{*}\right)$ yang diolah oleh SVPWM inverter menjadi arus 3 phase untuk menggerakkan motor induksi 3 phase sesuai dengan kecepatan referensi yang diinginkan. [8]

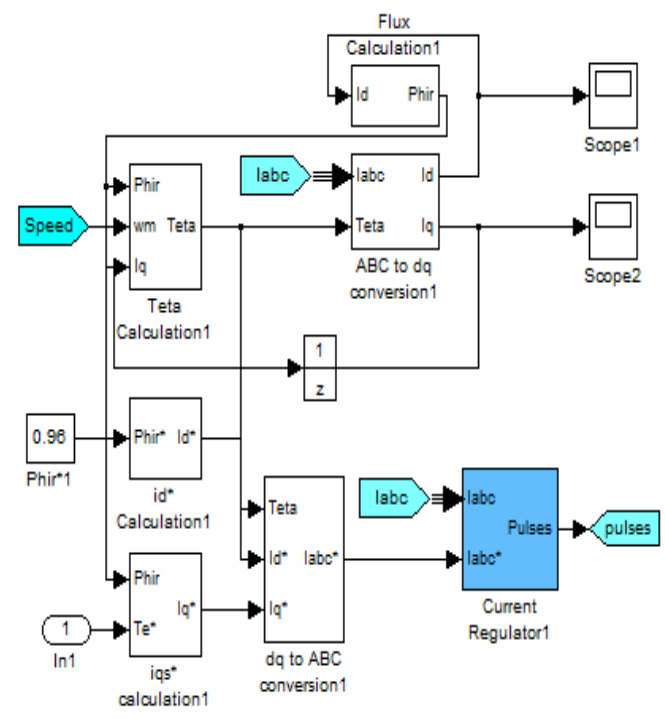

Gambar 6. Blok proses Vector control

Pada bagan ini dapat kita lihat bahwa vector control memiliki dua bentuk transformasi, yaitu transformasi clark untuk mengubah parameter 3 phase menjadi parameter 2 phase stasionari dan transformasi park yang berfungsi untuk mengubah parameter 2 phase stasionari menjadi dua phase rotasional. Dan pada bagian ini quadrature dan direct axis dapat diperoleh sehingga pengaturan torka dan medan dapat diatur secara terpisah.

Table 1. parameter of induction motor

\begin{tabular}{|l|l|l|}
\hline No. & Parameter & value \\
\hline 1. & Nominal power & $50 * 746 \mathrm{VA}$ \\
\hline
\end{tabular}

\begin{tabular}{|l|l|l|}
\hline 2. & Voltage line-line & $460 \mathrm{~V}$ \\
\hline 3. & Frequency & $60 \mathrm{~Hz}$ \\
\hline 4. & Stator resistance & $0.087 \mathrm{ohm}$ \\
\hline 5. & Induktansi stator & $0.8 \mathrm{e}-3 \mathrm{H}$ \\
\hline 6. & Rotor resistance & $0.228 \mathrm{ohm}$ \\
\hline 7. & Induktansi rotor & $0.8 \mathrm{e}-3 \mathrm{H}$ \\
\hline 8. & Mutual inductance & $34.7 \mathrm{e}-3 \mathrm{H}$ \\
\hline 9. & Momen inersia & $1.662 \mathrm{~J}$ \\
\hline 10. & Friction factor & $0.12 \mathrm{~F}$ \\
\hline
\end{tabular}

\section{HASIL DAN PEMBAHASAN}

\subsection{Hasil}

Adapun hasil output dasi pemodelan simulink yang telah dilakukan adalah :

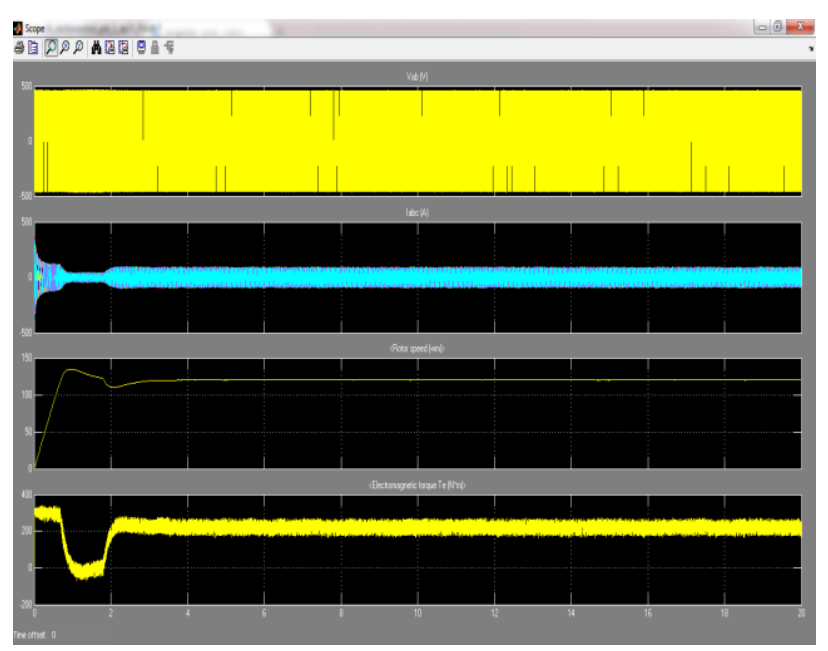

Gambar 7. Output vector control dengan speed reference $120 \mathrm{rpm}$, Vab, Iabc dan Torque

Pada grafik gambar 7, pada bagian Vab, dapat dilihat bahwa tegangan stabil pada nilai 480V. Pada grafik Iabc dapat dilihat 
bahwa saat start terjadi kenaikan, hal ini dikarenakan motor induksi membutuhkan arus yang cukup tinggi saat starting awal dikarenakan torsi awal saat motor induksi mulai bekerja membutuhkan nilai arus yang besar, saat motor telah mencapai kecepatan referensi, torsi lebih cendrerung stabil yang mengakibatkan nilai arus Iabc cenderung stabil pada nilai 40A. [5] Pada grafik kecepatan rotor dapat dilihat bahwa rotor mencapai kecepatan referensi membutuhkan waktu sebesar +/- 3s. Pada grafik torqe output, dapat kita lihat bahwa saat start torsi cukup besar, kemudian pada time respon $0.8 \mathrm{~s}$ nilai torsi turun kemudian normal kembali pada tim respon $2 \mathrm{~s}$.

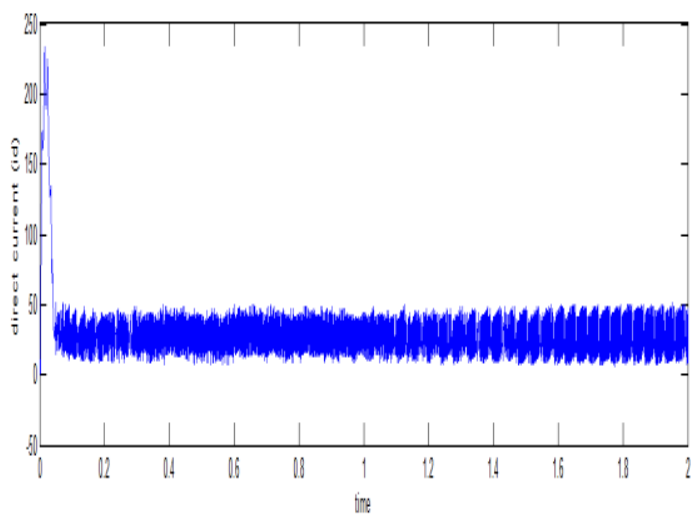

Gambar 8. Direct current (Id) parameter

Pada grafik gambar 8, dapat dilihat saat start mototr induksi membutuhkan nilai arus yang besar untuk memperoleh nilai torsi awal. Saat rotor telah mencapai kecepatan referensi, maka nilai Id akan lebih cenderung konstan pada nilai 48 A dengan time respon saat stabil pada nilai $0.05 \mathrm{~s}$.

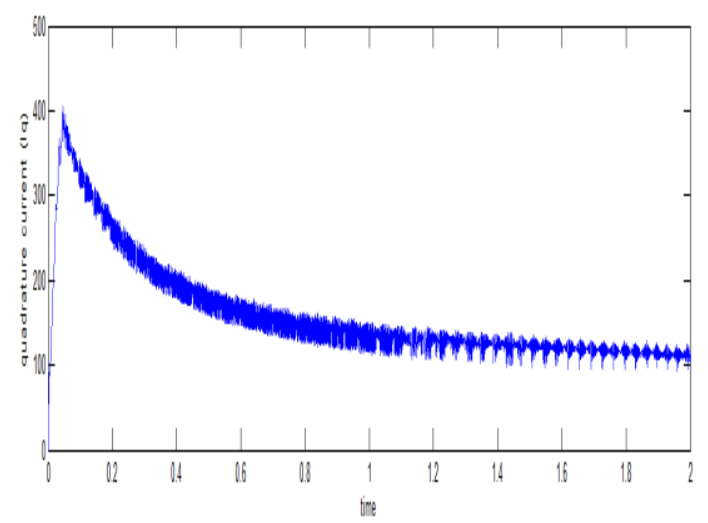

Gambar 9. Quadrature qurrent (Iq) parameter

Pada grafik gambar 9, dapat dilihat saat start mototr induksi membutuhkan nilai arus yang besar untuk memperoleh nilai torsi awal. Saat rotor telah mencapai kecepatan referensi, maka nilai Iq akan lebih cenderung konstan pada nilai $100 \mathrm{~A}$, namun hal ini memiliki respon time yang cukup besar, yaitu sekitar 1.4s.

\section{$\underline{\text { Analisa Hasil }}$}

pada grafik hasil simulasi dapat dilihat bahwa :

1. Penggunaan vector control dapat digunakan sebagai pendekatan dalam hal pengaturan kecepatan motor induksi. Dalam hal ini pendekatan yang dilakukan oleh vector control hanya berfungsi untuk mengubah parameter nonlinier (parameter motor ac) ke parameter linier (menyerupai motor $\mathrm{dc}$ ), sehingga jika parameter motor induksi yang tadinya non linier dapat diubah menjadi parameter linier, maka kecepatan motor induksi itu sendiri ikan lebih mudah untuk dikendalikan sesuai dengan referensi yang diinginkan. Pada simulasi dapat dilihat bahwa saat starting motor hingga mendekati referensi membutuhkan waktu yang cukup lama (3-4s) yang 
mengakibatkan terjadinya overshoot dan undershoot saat akan mencapai nilai referensi.

2. Parameter direct quadrature (d-q) sebanding dengan nilai perubahan respon pada output kecepatan rotor. Saat membutuhkan torsi awal, motor induksi membutuhkan arus yang besar sehingga nilai Id dan Iq juka saat awal sangat tinggi, akan tetapi saat mencapai kecepatan referensi dalam artian torsi yang sudah stabil, nilai Id dan Iq juga akan cenderung stabil

\section{KESIMPULAN}

Dari hasil percobaan dengan pemodelan menggunakan SIMULINK, maka diperoleh kesimpulan sebagai berikut :

1. Dalam kendali kecepatan motor induksi penggunaan Vector Control saja belum mampu manghasilkan performa yang baik, sehingga diperlukan adanya controller yang dapat memberikan tanggapan respon input yang baik, sehingga menghasilkan keluaran yang baik dengan nilai osilasi yang sangat kecil dan respon yang cepat.

2. Perubahan nilai kecepatan rotor dan torsi akan sebanding dengan perubahan nilai Id dan Iq pada motor induksi.

\section{DAFTAR PUSTAKA}

[1] C. C. Channand K. T. Chau, Member, IEEE, An Overview of Power Electronics in Electric Vehicles, IEEE Transactions on Industrial Electronics, vol. 44, no. 1, February 1997.

[2] Rene Jager, 'Fuzzy Logic in Control”, PhD Thesis, Delft University, Holland, 1995.
[3] Jerry M. Mendel, "Fuzzy Logic Systems for Engineering : A Tutorial", Proceedings of the IEEE, Vol. 83, no. 3, 1995, pp. 345-377.

[4] Nobuyoshi Mutoh, Satoru Kaneko, Taizou Miyazaki, Ryosou Masaki, and Sanshiro Obara, A Torque Controller Suitable for Electric Vehicles, IEEE Transactions On Industrial Electronics, vol. 44, no. 1, February 1997.

[5] Dong-Choon Lee, Seung-Ki Sul and Min-Ho Park, High PerformanceCurrent Regulator for a Field-Oriented Controlled Induction Motor Drive," IEEE Trans. on Industry Application, vol. 30, no. 5, pp. 1247-1257, 1994

[6] Mariam Khan, and Narayan C. Kar, Performance Analysis of Fuzzy Based Indirect Field Oriented Control of Induction Motor Drives for Hybrid Electric Vehicles, IEEE.

[7] S. Peresada, A. Tonielli, and R. Morici, "High-Performance Indirect FieldOriented Output-Feedback Control of Induction Motors," ElsevierScience, $S$. Peresada et al./ Automatica, vol. 35, pp.1033-1047, 1999

[8] Jae-Sung Yu, Sang-Hoon Kim, Fuzzy logic based Vector Control scheme for permanent magnet Synchronous motors in elevator drive applicantion, IEEE Trans on Industrial Electronics, Vol. 54 No. 4, Aug 2007.

[9] Peter Vas, Vector Control of AC Machines, Clarendon Press.

[10] Toshiaki Murata, Takeshi Tsuchiya and Ikuo Takeda, "Vector Control for Induction Machine on the Application of Optimal Control Theory," IEEE Trans. on Industrial Electronics, vol. 37, no. 4, pp. 283-290, 1990. 